conclude that at present no causal relation has been established. Results from the large case-control studies of childhood cancer currently in progress will be awaited with great interest.

GERALD DRAPER

Director

Childhood Cancer Research Group,

University of Oxford,

Oxford OX2 6HJ
1 National Radiological Protection Board. Repon of an advisory group on non-ionising radiation. Electromagnetic fields and the risk of cancer. Chilton: NRPB. 1992. (Documents of the NRPB. Vol 3 No. 1.)

2 Jones TL, Shih CH, Thurston DH, Ware BJ, Cole P. Selection bias from differentiated residential mobility as an explanation for associations of wire codes with childhood cancer. $7 \mathrm{Clin}$ Epidemiol 1993;46:891-5.

3 Olsen JH, Nielsen A, Schulgen G. Residence near high voltage facilities and risk of cancer in children. $B M 7$ 1993;307:891-5.

4 Verkasalo PK, Pukkala E, Hongisto MY, Valjus JE, Järvinen PJ, Heikkilä KV, et al. Risk of cancer in Finnish children living close to power lines. BMY 1993;307:895-9.

5 Feychting M, Ahlbom A. Magnetic fields and cancer in people residing near Swedish high voltage power lines. Stockholm: Karolinska Institutet. 1992. (IMM report 6/92.)

$6 \mathrm{Lin} \mathrm{SR,} \mathrm{Lu} \mathrm{PY.} \mathrm{An} \mathrm{epidemiologic} \mathrm{study} \mathrm{of} \mathrm{childhood} \mathrm{cancer} \mathrm{in} \mathrm{relation} \mathrm{to} \mathrm{residential} \mathrm{exposure} \mathrm{to}$ electromagnetic fields (abstract). In: Department of the Environment, EPRI. Contractors' meeting.
Portland, Oregon: DoE/EPRI, 1989.

\title{
Free radicals and vascular disease: how much do we know?
}

\section{They have a role in the function of the normal endothelium and in atherosclerosis}

The vascular endothelium is a selectively permeable barrier between the blood and the vessel walls. It is not a passive barrier, however: endothelial cells play an important part in controlling vessel tone, vascular permeability, platelet aggregation, and the adherence of phagocytes such as neutrophils and monocytes. At sites of inflammation neutrophils adhere to the endothelium before entering the inflamed tissue and the endothelial permeability increases. The vascular endothelium can release many products including prostacyclin, adenosine, endothelins, and platelet activating factor.

The vascular endothelium also secretes a free radical, nitric oxide $\left(\mathrm{NO}^{\circ}\right)$, the endothelium derived relaxing factor. ${ }^{2}$ (A free radical, denoted by a superscript dot, is an atom or molecule with one or more unpaired electrons; an unpaired electron is a lone electron in an orbital.) $\mathrm{NO}^{\bullet}$ inhibits platelet aggregation and adherence of neutrophils and is a powerful vasodilator. ${ }^{2}$ Endothelial cells also generate another radical, superoxide $\left(\mathrm{O}_{2}{ }^{-}\right)$, in vitro. ${ }^{3}$ Whether endothelial cells release superoxide all the time in vivo, or whether only after an insult (such as ischaemia and reperfusion) is unknown.

When two free radicals meet they can join their unpaired electrons and form a non-radical. Superoxide and $\mathrm{NO}^{\circ}$ react quickly to form ONOO- ${ }^{4}$ As a result, superoxide antagonises the vasodilatory action of $\mathrm{NO}^{\bullet}$ and adding superoxide dismutase (an enzyme that scavenges superoxide) prolongs the life of $\mathrm{NO}^{\circ}$. Indeed, it has been suggested that vascular over-production of superoxide might be one cause of hypertension. ${ }^{5}$ A further suggestion is that the ONOO- (peroxynitrite) produced by the reaction between superoxide and $\mathrm{NO}^{\circ}$ is itself cytotoxic. ${ }^{6}$ Hence, the generation of superoxide by vascular endothelium and its interaction with $\mathrm{NO}^{\circ}$ both warrant further investigation.

Endothelial cells can be killed by high concentrations of hydrogen peroxide by mechanisms that involve damage to DNA and proteins caused by free radicals as well as an increased concentration of intracellular free calcium ions. ${ }^{78}$ Low concentrations of hydrogen peroxide are, however, efficiently dealt with by catalase and glutathione peroxidase, enzymes that metabolise hydrogen peroxide in the endothelium. ${ }^{9}$ Indeed, sublethal exposure of endothelium to hydrogen peroxide (for example, produced by neutrophils adhering to endothelium) might contribute to the increases in vascular permeability, the synthesis of platelet activating factor and tissue plasminogen activator, and the adhesion of more neutrophils to the endothelium. ${ }^{10}$

Endothelial cells can also be injured by high concentrations of organic peroxides, such as the lipid peroxides produced when free radicals attack polyunsaturated fatty acid side chains and cholesterol in membranes and lipoproteins.
Fortunately, the lipid peroxide concentration in plasma from healthy humans is submicromolar. ${ }^{11}$ Concentrations are, however, higher in hyperlipidaemic patients, even during treatment with lipid lowering drugs, although whether concentrations are high enough to injure the endothelium is unknown.

Injury to endothelium by chemical or mechanical means or by infection with certain viruses may lead to atherosclerosis. ${ }^{1213}$ Evidence is accumulating that reactions involving free radicals, especially peroxidation of low density lipoproteins in vessel walls, are major contributors to the development of atherosclerosis. ${ }^{13}$ Thus low density lipoprotein in the early stages of peroxidation promotes adherence of monocytes to endothelium. ${ }^{14}$ Monocytes develop into macrophages within the vessel wall: both cell types can generate superoxide and hydrogen peroxide, and macrophages may also generate $\mathrm{NO}^{\circ}$. Extensively peroxidised low density lipoprotein can be taken up by macrophages to form "foam cells" laden with lipid, which are present even in early atherosclerotic lesions. ${ }^{12}$ Smoking aggravates atherosclerosis and imposes a powerful stress due to free radicals on the human body. ${ }^{15} \mathrm{An}$ adequate dietary intake of vitamin $\mathrm{E}$ seems protective against vascular disease, perhaps because vitamin $\mathrm{E}$ inhibits peroxidation of lipids. ${ }^{13}$ How much is adequate is another unanswered question; despite recent enthusiasm for dietary supplementation with "antioxidant" nutrients (such as vitamins $E$ and $C$ and the carotenoids) we do not know what dietary intakes are optimal.

In the early days of research into free radicals scientists concentrated on their damaging effects. Indeed, they are damaging in excess (even too much $\mathrm{NO}^{\circ}$ is cytotoxic, destroying mitochondrial iron-sulphur proteins). But now we know that free radicals are often useful in small amountsfor example, as important agents killing foreign organisms ingested by phagocytes and as mediators of some of the effects of acute inflammation. ${ }^{101214}$ An important clinical question is the extent to which antioxidants could prevent or treat the devastating effects of advanced atherosclerosis. ${ }^{12} 1316$

BARRY HALLIWELL

Pharmacology Group, King's College,

Professor of medical biochemistry

University of London,

London SW3 6LX

1 Lefer AM, Lefer DJ. Pharmacology of the endothelium in ischemia-reperfusion and circulatory hock. Ann Rev Pharmacol Toxicol 1993;33:71-90.

2 Moncada S, Palmer RMJ, Higgs EA. Nitric oxide: physiology, pathophysiology and pharmacology. Pharmacol Rev. 1991;43:109-42.

3 Arroyo CM, Carmichael AJ, Bouscarel B, Liang JH, Weglicki WB. Endothelial cells as a source of oxygen free radicals: an ESR study. Free Radical Research Communications 1990;9:287-96.

4 Huie RE, Padmaja S. The reaction of NO with superoxide. Free Radical Research Communication 1993;18:195-9.

5 Nakazono K, Watanabe N, Matsuno K, Sasaki J, Sato T, Inoue M. Does superoxide underlie the pathogenesis of hypertension? Proc Natl Acad Sci USA 1991;88:10045-8. 
6 Beckman JS, Beckman TW, Chen J, Marshall PA, Freeman BA. Apparent hydroxyl radical production by peroxynitrite: implications for endothelial injury from nitric oxide and production by peroxynitrite: implications for

7 Thies RL, Autor AP. Reactive oxygen injury to cultured pulmonary artery endothelial cells: mediation by poly (ADP-ribose) polymerase activation causing NAD depletion and altered energy balance. Arch Biochem Biophys 1991;286:353-63.

8 Geeraerts MD, Ronveaux-Pupal MF, Lemasters LL, Herman B. Cytosolic free $\mathrm{Ca}^{2}+$ 'nd proteolysis in lethal oxidative injury in endothelial cells. Am $\mathcal{F}$ Physiol 1991;261:C889-96.

9 Verkerk A, Jongkind JF. Vascular cells under peroxide-induced oxidative stress: a balance study on in vitro peroxide handling by vascular endothelial and smooth muscle cells. Free Radical Research Communications 1992;17:121-32.

10 Bradley JS, Johnson DR, Pober JS. Endothelial activation by hydrogen peroxide. Am f Path 1993;142:1598-609.
11 Bowry VW, Stanley KK, Stocker R. High density lipoprotein is the major carrier of lipid hydroperoxides in human blood plasma from fasting donors. Proc Natl Acad Sci USA hydroperoxides in

12 Ross R. The pathogenesis of atherosclerosis: a perspective for the 1990s. Nature 1993;362:801-9. 13 Leake DS. Oxidized low density lipoproteins and atherogenesis. Br Heart f 1993;69:476-8.

14 Parhami F, Fang ZT, Fogelman AM, Andalibi A, Territo MC, Berliner JA. Minimally modified low density lipoprotein-induced inflammatory responses in endothelial cells are mediated by cyclic adenosine monophosphate. $\mathcal{F}$ Clin Invest 1993;92:471-8

15 Halliwell B, Gutteridge JMC. Free radicals in biology and medicine. 2nd ed. Oxford: Clarendon Press, 1989.

16 Ferns GAA, Forster L, Stewart-Lee A, Nourooz-Zadeh J, Anggård EE. Probucol inhibits mononuclear cell adhesion to vascular endothelium in the cholesterol-fed rabbit. Atherosclerosis 1993;100:171-81.

\section{Alternative career paths for doctors}

\section{Is the NHS facing up to its responsibilities as an employer?}

In many careers the concept of a single job for life is being challenged-most recently by the Sheehy Report on the police. ${ }^{1}$ In a personal view this week Liz Welsh argues that plateaus in medical careers are boring (p 944) ${ }^{2}$ and that the medical profession must loosen up.

The development of a trend in hospital medicine away from single jobs for life will pose severe difficulties. Firstly, doctors make very considerable personal investment in time for training up to specialist grade. Secondly, after 15 or 20 years doing the same sort of work consultants wanting some new challenge may find their age a barrier to changing.

After graduation mechanisms for appraisal and career development are inadequate especially for those who want to look beyond the boundaries of the profession. Furthermore, formidable obstacles hinder moves away from hospital practice due partly to the limited number of suitable opportunities but mainly to the rigidity of the training and accreditation systems of the royal colleges and the perverse incentives of the reward structure, particularly the merit award system. Hearsay suggests that dissatisfaction at this is more widespread than it seems on the surface; if so, it would be desirable to determine the true extent of the problem.

That the NHS as a near monopoly employer does not seem to accept responsibility for the career development of doctors is a matter for concern. What is needed is a system for regular assessment of individual performance to identify potential both for the development of existing skills and for the acquisition of new ones. The needs for training and development have to be defined and mutually agreed on. For hospital doctors this could start from some form of peer review of clinical performance, which would identify career development needs (beyond clinical practice for those wishing to explore alternative career paths). Such an appraisal system should identify people's needs as early as possible because of the time it takes to train them in new skills. Thus a system is needed both to facilitate change and to identify those doctors who may - or perhaps should-be considering it.

A critical factor operating against career development at consultant level is the structure of hospital practice. In a firm of two consultants even study leave can be difficult to organise; a much larger firm would provide greater flexibility. Although a larger team approach would make career development and appraisal easier, it would raise issues such as the recognition of seniority among consultants and the safeguarding of the training of junior doctors.

Because of the extent to which they dictate the use of resources doctors' potential contribution to NHS management has been recognised; and indeed implicit in the recent reforms is the expectation that doctors will increasingly take up part time and full time management roles. With the introduction of medical directors, clinical directorates, and the develop- ment of clinical audit the NHS is recognising the need for people with wide experience. But the requirements of these jobs must be considered in conjunction with the planned career development of the people who will fill them.

As the NHS goes through a period of change new opportunities are arising. Changes in doctors' careers must be seen as normal, and doctors seeking to change their careers must be actively assisted to do so. Doctors need to examine their own position in the light of what the NHS expects of them and of their ability and need to change. For doctors exploring career development, there is a spectrum of options ranging from complete change to the introduction of new activities into existing work patterns. As a major employer, the NHS urgently needs to establish a culture in which career development and change are the norm and are recognised as equally important to the organisation and to the individual person.

Given adequate resources, postgraduate deans would seem particularly well placed to contribute. As "programme directors" based in regions, they could plan and organise assessment, guidance, and training schemes. Consideration might be given to piloting an experimental system of professional relicensing, which would have the effect of separating professional appraisal from individual contracts of employment. Alternatively, an institution based approach could focus on the professional development of individual junior staff but become increasingly concerned with departmental performance and the needs of the institution for those in higher grades. A system of rolling contracts with built in reviews might in the long run be better than the current (effectively) tenured position for senior staff.

Within this framework, the special positions of both small trusts and academic medical staff need to be taken into account. Appraisal in general practice presents a different set of problems because of the different context in which general practitioners work. Formal recognition of the importance of the problem might be helped by the creation of a small number of fellowships for a graduate course in management and administration, restricted to young doctors who have completed their clinical training and who wish to enter the NHS management structure.

MICHAEL ASHLEY-MILLER MAX LEHMANN

Nuffield Provincial Hospitals Trust,

59 New Cavendish Street,

London WIM 7RD

Although these are the authors' views, many of the ideas were expressed at a recent seminar involving senior representatives of the medical profession, industrialists, and several health services managers.

1 Inquiry into Police Responsibilities and Rewards. HMSO: 1993. (Cmnd 2280.) 2 Welsh EA. Plateaus are boring. $B M \mathcal{F}$ 1993;307:944. 